\title{
Overactive bladder in an integrated delivery system: a longitudinal cohort study
}

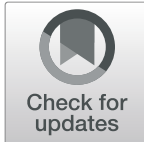

Jeffrey A. Linder ${ }^{* *}$ D, Joel S. Weissman², Harry Reyes Nieva ${ }^{3}$, Stuart Lipsitz² ${ }^{2}$ R. Sterling Haring ${ }^{4}$, Julie DeAngelis ${ }^{5}$, Rita M. Kristy ${ }^{5}$ and Kevin R. Loughlin ${ }^{6}$

\begin{abstract}
Background: Overactive bladder $(\mathrm{OAB})$ is common and morbid. Medication and diagnosis claims may be specific, but lack sensitivity to identify patients with overactive bladder. We used an "electronic health record (EHR) phenotype" to identify cases and describe treatment choices and anticholinergic burden for OAB.

Methods: We conducted a retrospective cohort study in a large, integrated health delivery system between July 2011 and June 2012 (2-year follow-up). We examined care from primary care and specialty clinics, medication and procedure use, and anticholinergic burden for each patient.

Results: There were 7362 patients with an EHR OAB phenotype; $50 \%$ of patients were $>65$ years old, $74 \%$ were female, and $83 \%$ were white. The distribution of care included primary care physician (PCP)/specialty comanagement (25\% of patients); PCP care only (18\%); urology only (13\%); or some other combination of specialty care (33\%). Only $40 \%$ of patients were prescribed at least 1 OAB medication during the study. The mean duration of prescribed medication was 1.5 months ( $95 \%$ confidence interval [CI], 1.4 to 1.6 months; range, $<1$ month to 24 months). Independent predictors of receipt of an $O A B$ medication included increasing age (odds ratio [OR], 1.4 for every 10 years; $95 \% \mathrm{Cl}, 1.4$ to 1.5), women (OR, 1.6 compared with men; $95 \% \mathrm{Cl}, 1.4$ to 1.8$)$, diabetes $(\mathrm{OR}, 1.3 ; 95 \% \mathrm{Cl}$, 1.1 to 1.5$)$, and certain sources of care compared with PCP-only care: PCP/specialty co-management (OR, 1.8; 95\% $\mathrm{Cl}, 1.5$ to 2.0), urology (OR, 2.2; $95 \% \mathrm{Cl}, 1.8$ to 2.6), and multiple specialists (OR, 1.4; $95 \% \mathrm{Cl}, 1.2$ to 1.8). Very few patients received other treatments: biofeedback $(<1 \%)$, onabotulinumtoxinA $(2 \%)$, or sacral nerve stimulation (1\%). Patients who received $O A B$ medications had significantly higher anticholinergic burden than patients who did not (anticholinergic total standardized daily dose, 125 versus $46 ; P<.001$ ).
\end{abstract}

Conclusions: Although OAB is common and morbid, in a longitudinal study using an EHR OAB phenotype 40\% of patients were treated with $O A B$ medication and only briefly.

Keywords: Antimuscarinics, Anticholinergic burden, Electronic health records, Integrated delivery system, Medication and procedure use, Overactive bladder, Overactive bladder syndrome, Primary and specialty care, Urgency, Urinary incontinence

\footnotetext{
* Correspondence: jlinder@northwestern.edu

Prior presentation: A preliminary version of this analysis was presented at the Academy of Managed Care Pharmacy, October 3-6, 2016, National Harbor, MD.

'Division of General Internal Medicine and Geriatrics, Northwestern University Feinberg School of Medicine, 750 N. Lake Shore Drive, 10th Floor, Chicago, IL 60611, USA

Full list of author information is available at the end of the article
}

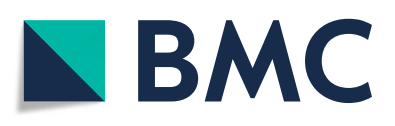

(- The Author(s). 2020 Open Access This article is licensed under a Creative Commons Attribution 4.0 International License, which permits use, sharing, adaptation, distribution and reproduction in any medium or format, as long as you give appropriate credit to the original author(s) and the source, provide a link to the Creative Commons licence, and indicate if changes were made. The images or other third party material in this article are included in the article's Creative Commons licence, unless indicated otherwise in a credit line to the material. If material is not included in the article's Creative Commons licence and your intended use is not permitted by statutory regulation or exceeds the permitted use, you will need to obtain permission directly from the copyright holder. To view a copy of this licence, visit http://creativecommons.org/licenses/by/4.0/. The Creative Commons Public Domain Dedication waiver (http://creativecommons.org/publicdomain/zero/1.0/) applies to the data made available in this article, unless otherwise stated in a credit line to the data. 


\section{Background}

Overactive bladder $(\mathrm{OAB})$ is defined by the International Continence Society (ICS) as a symptom syndrome defined by urinary urgency, frequency, and nocturia, with or without incontinence [1-3]. OAB is common and its prevalence can vary widely depending on the patient population and disease definition, affecting $7-27 \%$ of men and $9-43 \%$ of women $[1,2]$. OAB is associated with impaired sleep quality, depression, falls, fractures, social isolation, and worse quality of life $[1,3]$.

OAB can be difficult-to-treat in part because of the anticholinergic side effects of the most commonly prescribed medications. Recently, anticholinergic medications, including OAB medications, have been implicated in the development of cognitive impairment and dementia $[4,5]$.

$\mathrm{OAB}$ is underreported by patients and poorly recognized in primary care [6]. OAB may also be underrecognized by specialists in integrated health systems. Prior studies have been limited by use of claims or prescribing data to identify OAB patients, which may focus only on highly-specified patient populations who have multiple visits for $\mathrm{OAB}$, an explicit diagnosis of $\mathrm{OAB}$, or OAB medication prescriptions [7-9]. Such methods may misclassify patients who present with the complex of symptoms that define $\mathrm{OAB}$. In addition, prior studies have not described care of patients with $O A B$ within an integrated delivery system utilizing electronic health records (EHRs), in which patients could receive care from some combination of primary and specialty care, including urology, gynecology, and urogynecology.

EHR-based disease phenotypes have the potential to more sensitively identify patient cohorts [10, 11]. Based on an initial chart review, modification, and refinement, EHR phenotypes use a mix of coded data and free-text criteria to identify patients with target conditions. EHR phenotypes are particularly useful for conditions like $\mathrm{OAB}$ that do not have reliable, well-defined diagnostic criteria (e.g., simply using International Statistical Classification of Diseases and Related Health Problems-9 [ICD-9] codes for OAB).

The aim of this study was to identify patients with an EHR OAB phenotype and conduct a health systembased, longitudinal cohort assessment to describe care by different specialties, medication use, and procedures, as well as to assess the anticholinergic burden of patients who did and did not receive $\mathrm{OAB}$ medications.

\section{Methods}

\section{Setting, data source, and overview}

Partners HealthCare is an integrated health delivery system that provides primary and specialty care in Eastern Massachusetts. The system has eight acute care hospitals including Brigham and Women's Hospital and Massachusetts General Hospital. Partners HealthCare includes approximately 1000 primary care physicians (PCPs) and about 5500 specialists. All Partners HealthCare entities share a common data infrastructure.

Because of limitations of prior methods of identifying patients with $\mathrm{OAB}$, we developed an OAB EHR phenotype through identification of coded fields, a pilot chart review, a definitive chart review, and EHR model training. We retrospectively identified Partners HealthCare patients using an OAB EHR phenotype - a combination of structured variables and natural language processing of free text - who met criteria for OAB between July 1, 2011 and June 30, 2012 [10, 11]. We followed patients from their index visit - the date on which they met criteria for $\mathrm{OAB}$ - for 2 years. We examined visit, medication, and utilization data (Fig. 1).

\section{EHR OAB phenotype \\ Identification of OAB-related coded fields}

The development of the OAB EHR phenotype began with two clinician investigators (JAL, KRL), with input from the rest of the study team, identifying 37 ICD-9 diagnosis codes, medications, or problem list entries that could be potentially associated with OAB (Supplementary Table 1). ICD-9 codes included "hypertonicity of bladder," "retention of urine," "urgency of urination," and others. Problem list entries included "bladder dysfunction," "hyperactive bladder," "urgent desire to urinate," and others. We designated each of the 37 variables as either "highly likely" to be associated with a patient who had a diagnosis of $O A B$ or "likely" to be associated with a diagnosis of OAB.

\section{Pilot chart review}

To determine the most efficient sample size for a larger chart review, JAL and KRL conducted a pilot chart

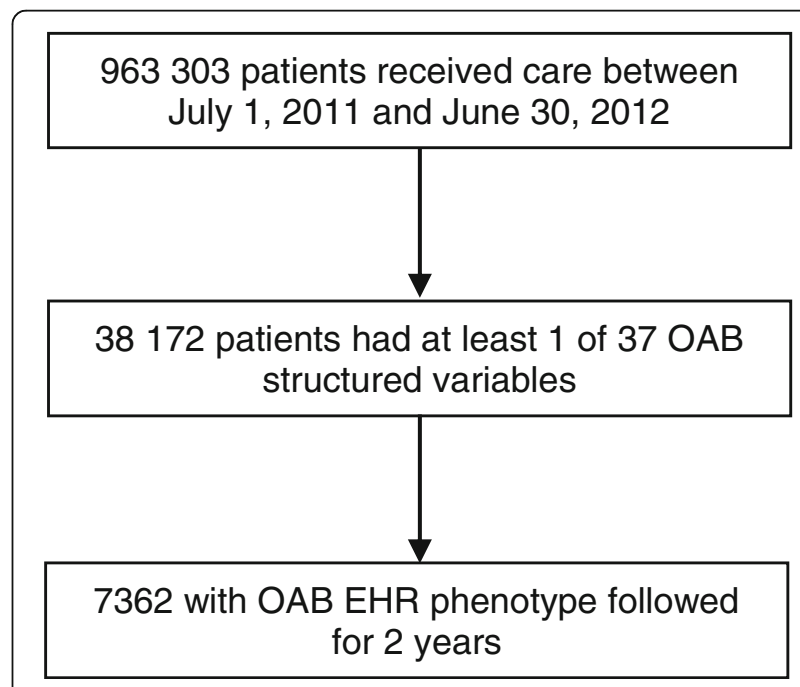

Fig. 1 Patient Flow. OAB, overactive bladder; EHR, electronic health record 
review of 20 charts with a highly likely code, 20 charts with only a likely code, and 20 charts with no OABrelated code. On chart review, highly likely codes had a positive predictive value of $70 \%$, likely codes had a positive predictive value of $35 \%$, and, for charts with no OAB-related code a PPV of $0 \%$. Based on these estimates for the PPV of highly-likely and likely codes and the distribution of highly-likely and likely codes, we determined that, a sample size of 729 reviewed charts would yield a 95\% CI (i.e., the 95\% CI for the PPV would be at most $10 \%$ wide). We subsequently identified patients 18 years or older who had any of these 37 diagnosis codes, medications, or problem list entries.

\section{Definitive chart review}

Three physician reviewers examined a random sample of 729 charts to identify those which met pre-specified, database collected and calculated criteria, consistent with ICS and International Consultation on Incontinence definitions, for a clinical diagnosis of OAB [12]. For the chart review, we created four phenotype classifications (definite, probable, possible, and not $O A B$ ) based on a combination of features including the results of urodynamic testing or, in the absence of urodynamic testing, documentation in patient notes. Patients were considered to have definite $\mathrm{OAB}$ if they had urodynamic testing results of detrusor hyperreflexia, detrusor instability, uninhibited contraction, or equivalent language. For the vast majority of patients who did not have urodynamic testing, we required chart documentation of 3 symptoms: 1) urinary urgency in the absence of urinary tract infection, history of genitourinary procedure within the past 90 days, or other obvious pathology, 2) urinary frequency (voiding eight or more times or an unknown quantity per day), and 3) nocturia (awakening two or more times or an unknown number to void). We defined urgency as a sudden, compelling need to void which is difficult to defer. A patient was classified as having definite $\mathrm{OAB}$ if they had urgency, frequency, and nocturia; probable $\mathrm{OAB}$ if they had urgency and frequency; possible $\mathrm{OAB}$ if they had only urgency; and not $\mathrm{OAB}$ if they had none of the symptoms or had an alternative cause of symptoms. If a urinalysis showed five or more white blood cells per high power field, we required a negative culture to rule out alternate cause of urgency.

Reviewers also responded to the prompt, "Do you agree or disagree with the assigned category of the $\mathrm{OAB}$ diagnosis?" using a 4-point Likert scale (completely agree, partially agree, partially disagree, completely disagree). We considered $\mathrm{OAB}$ cases as those which were classified as definite $O A B$ with which the reviewer completely agreed; definitely $\mathrm{OAB}$ with which the reviewer partially agreed; or classified as probable $\mathrm{OAB}$ with which the reviewer completely agreed.

\section{$O A B$ EHR phenotype based on coded fields and free-text} To develop our OAB EHR phenotype, we randomly selected $70 \%$ of patients classified by chart review for training and held the remaining 30\% for the testing set. We trained an L1-regularized (Least Absolute Shrinkage and Selector Operator, LASSO) [13, 14] logistic regression using the gold standard labels assigned from chart review ( 1 for OAB; 0 otherwise) as the dependent variable and the coded and free-text elements in the EHR as model features. We incorporated free-text from outpatient clinical notes into our phenotyping algorithm via natural language processing. We aggregated all outpatient clinical notes into a single document for each patient and employed a "bag-of-words" (BOW) representation.

As determined a priori, we set the predictive probability of the LASSO model to maximize the sum of sensitivity and specificity (NLP-only model: sensitivity, 48\%; specificity, 84\%; c-statistic, 0.64; NPV, 89\%; PPV, 37\%). For the final predictive model, because we intended to examine medications as an outcome, we omitted medications as a coded field, sacrificing some PPV. The final model (Supplementary Table 2) had a sensitivity of 54\%, specificity of $80 \%$, c-statistic of 0.72 , negative predictive value of $83 \%$, and, consistent with our pilot and final chart review, a PPV of 54\% (see Discussion).

\section{Data extraction and analysis}

For cases that met the EHR phenotype definition of $O A B$, we extracted sociodemographic information including age, sex, race/ethnicity, primary language, insurance type, and marital status. Sociodemographic information was collected during patient registration at Partners HealthCare sites. In addition, we used the EHR problem list and diagnosis entries to determine if the patient had moderate-to-severe chronic kidney disease; chronic obstructive pulmonary disease; congestive heart failure; or diabetes mellitus (Supplementary Table 3). We also examined two relative contraindications to anticholinergic treatment: glaucoma and dementia.

We classified patients according to what specialties cared for the patient (source of care) over the following 2 years. We classified patients' source of care as PCP only; a single "OAB-related specialist," including urology, gynecology, or urogynecology; a combination of OABrelated specialists; co-management by a $\mathrm{PCP}$ and any OAB-related specialists; or other (ie, patients who did not receive care from a $\mathrm{PCP}$, urologist, gynecologist, or urogynecologist).

We identified the first OAB-related medication that patients received during follow-up, including darifenacin, fesoterodine, flavoxate, hyoscyamine, imipramine, mirabegron, oxybutynin, solifenacin, tolterodine, and trospium. Among patients who received an $\mathrm{OAB}$ medication, we measured the number of different medications prescribed to individual patients over 2 years of follow-up. In 
addition, we measured the total number of months of medication each patient was prescribed and calculated the average duration of medication prescription coverage among patients who received any medication. We used Current Procedural Terminology (CPT) codes to identify procedures including biofeedback, onabotulinumtoxinA injections, and sacral nerve stimulation (Supplementary Table 4).

We measured anticholinergic burden of $\mathrm{OAB}$ and non$\mathrm{OAB}$ medications using the method of Gray and colleagues $[5,15]$. Briefly, we multiplied the medication strength by the number of units of medication dispensed to calculate a total medication dose for each anticholinergic medication, the anticholinergic total standardized daily dose (TSDD). We then converted the total dose for each medication into a standardized daily dose by dividing by the minimum reported effective dose of each medication. We then added the standardized daily dose across medications to calculate a TSDD for anticholinergic medications and examined the difference in anticholinergic TSDD between those who did and did not receive $\mathrm{OAB}$ medications.

\section{Statistical analysis}

We described basic associations using proportions. We compared proportions - including sociodemographic, clinical, and treatment difference between men and women - using the chi-squared test. To examine independent predictors of receipt of $O A B$ medications, we used multivariable logistic regression. We modeled age in decades and omitted insurance status, which was strongly colinear with age. Language was also omitted, as it was strongly colinear with race/ethnicity. We used the linear trend test to assess the relationship between number of $\mathrm{OAB}$ medications prescribed during the study period and increasing TSDD. For all analyses we used SAS (version 9.4, Cary, NC) and considered $P$ values $<.05$ significant.

\section{Results}

\section{Cohort derivation and characteristics}

Of the 963,303 patients with EHR records during the study period, 38,172 had at least one coded variable that was potentially related to OAB. Of these, 7362 patients had an OAB EHR phenotype without medications as predictors. Of these patients, $50 \%$ were over 65 years old, $74 \%$ were female, and $83 \%$ were white (Table 1 ). In total, $45 \%$ of patients had private insurance, $47 \%$ had Medicare, and 5\% had Medicaid. Comorbid conditions included chronic obstructive pulmonary disease (20\%), diabetes (17\%), congestive heart failure (9\%), chronic kidney disease (4\%), glaucoma (3\%), and dementia (3\%).

\section{Sources of care}

The distribution of care included primary care/specialty co-management (for $25 \%$ of patients); primary care only
(17\%); urology only (13\%); or another combination of specialty care (33\%; Table 2). Men were more likely to get care from urologists and essentially did not receive care from gynecologists or urogynecologists.

\section{Medication use, classes, and persistence}

Only $40 \%$ of patients received an OAB-related medication in the 2 years of follow-up. The most commonly prescribed medications were oxybutynin, tolterodine, and solifenacin. Patients who were co-managed by PCPs and a specialist had the highest medication receipt rate (48\%), followed by patients seen by urogynecologists (47\%), urologists (45\%), a combination of specialists (41\%), PCPs only (38\%), other specialties (34\%), and gynecologists only $(30 \%)(p<.001)$; Supplementary Table 5 and Supplementary Table 6). Among patients with contraindications for anticholinergic treatment, 54\% (127/ $236)$ of those with dementia and $46 \%(115 / 249)$ of those with glaucoma received $\mathrm{OAB}$ medication.

Among patients who received medications, the median number of OAB-related medications received in the subsequent 2 years was two (interquartile range, two to three; range one to seven). Among patients who received medication, the average duration of prescribed medication was 1.5 months (95\% confidence interval [CI] 1.41.6 months; range, $<1-24$ months).

In multivariable modeling, independent predictors of receipt of an $\mathrm{OAB}$ medication were increasing age (odds ratio [OR] 1.4 for every 10 years; $95 \%$ CI, $1.4-$ 1.5), female sex (OR, 1.6 compared with male; $95 \%$ $\mathrm{CI}, 1.4-1.8$ ), other marital status (OR, 0.5 compared with married; 95\% CI, 0.4-0.6), widowed (OR, 0.7 compared with married; 95\% CI, 0.6-0.9), diabetes (OR, 1.3; 95\% CI, 1.1-1.5), and certain sources of care compared with $\mathrm{PCP}$-only care: $\mathrm{PCP} /$ specialist co-management (OR, 1.8; 95\% CI, 1.5-2.0), multiple specialists (OR, 1.4; 95\% CI, 1.2-1.8), urogynecology (OR, 1.9; 95\% CI, 1.2-3.1), and urology (OR, 2.2; 95\% CI, 1.8-2.6). Marginally significant predictors of $\mathrm{OAB}$ medication prescribing were Hispanic race/ethnicity (OR, 1.3 compared with whites; 95\% CI, 1.01.7) and chronic obstructive pulmonary disease (OR, 1.1; $95 \% \mathrm{CI}, 1.0-1.3$ ).

\section{Other treatments}

Few patients received other treatments of any type. Less than $1 \%$ of patients received biofeedback, $2 \%$ of patients received onabotulinumtoxin $\mathrm{A}$, and $1 \%$ of patients received sacral nerve stimulation.

\section{Anticholinergic burden}

Over the 2-year follow-up, patients who received $O A B$ medications had significantly higher anticholinergic burden than patients who did not (anticholinergic TSDD, 
Table 1 Cohort Characteristics by Sex

\begin{tabular}{|c|c|c|c|c|}
\hline \multirow[t]{2}{*}{ Characteristic } & Overall $(n=7362)$ & Female $(n=5417)$ & Male $(n=1945)$ & $P$ value \\
\hline & \multicolumn{4}{|l|}{ No. (column \%) } \\
\hline Less than 65 years old & $3646(50)$ & $2797(52)$ & 849 (44) & $<.001$ \\
\hline 65 years old or older & $3716(50)$ & $2620(48)$ & $1096(56)$ & \\
\hline Total & $7362(100)$ & $5417(100)$ & $1945(100)$ & \\
\hline \multicolumn{5}{|l|}{ Race/ethnicity } \\
\hline White/Caucasian & $6103(83)$ & $4516(83)$ & $1587(82)$ & .012 \\
\hline Black/African American & $338(5)$ & $233(4)$ & $105(5)$ & \\
\hline Hispanic/Latino & $270(4)$ & $211(4)$ & $59(3)$ & \\
\hline Asian/Pacific Islander & $125(2)$ & $82(2)$ & $43(2)$ & \\
\hline Other/unknown & $526(7)$ & $375(7)$ & $151(8)$ & \\
\hline Total & $7362(100)$ & $5417(100)$ & $1945(100)$ & \\
\hline \multicolumn{5}{|l|}{ Language } \\
\hline English & $6704(91)$ & $4933(91)$ & $1771(91)$ & .011 \\
\hline Spanish & $310(4)$ & $245(5)$ & $65(3)$ & \\
\hline Other/unknown & $348(5)$ & $239(4)$ & $109(6)$ & \\
\hline Total & $7362(100)$ & $5417(100)$ & $1945(100)$ & \\
\hline \multicolumn{5}{|l|}{ Insurance } \\
\hline Private & $3344(45)$ & $2489(46)$ & 855 (44) & $<.001$ \\
\hline Medicare & $3428(47)$ & $2467(46)$ & $961(49)$ & \\
\hline Medicaid & $362(5)$ & $272(5)$ & $90(5)$ & \\
\hline None & $228(3)$ & $189(3)$ & $39(2)$ & \\
\hline Total & $7362(100)$ & $5417(100)$ & $1945(100)$ & \\
\hline \multicolumn{5}{|l|}{ Marital status } \\
\hline Married/partnered & $3522(48)$ & $2417(45)$ & $1105(57)$ & $<.001$ \\
\hline Single & $1591(22)$ & $1166(22)$ & $425(22)$ & \\
\hline Widowed & $979(13)$ & $865(16)$ & $114(6)$ & \\
\hline Divorced/separated & $757(10)$ & $618(11)$ & $139(7)$ & \\
\hline Other/unknown & $513(7)$ & $351(6)$ & $162(8)$ & \\
\hline Total & $7362(100)$ & $5417(100)$ & $1945(100)$ & \\
\hline \multicolumn{5}{|l|}{ Comorbidities } \\
\hline Chronic kidney disease (moderate/severe) & $293(4)$ & $175(3)$ & $118(6)$ & $<.001$ \\
\hline No chronic kidney disease (moderate/severe) & $7069(96)$ & $5242(97)$ & $1827(94)$ & \\
\hline Total & $7362(100)$ & $5417(100)$ & $1945(100)$ & \\
\hline Chronic obstructive pulmonary disease & $1504(20)$ & $1169(22)$ & $335(17)$ & $<.001$ \\
\hline No chronic obstructive pulmonary disease & $5858(80)$ & $4248(78)$ & $1610(83)$ & \\
\hline Total & $7362(100)$ & $5417(100)$ & $1945(100)$ & \\
\hline Congestive heart failure & $694(9)$ & $439(8)$ & $255(13)$ & $<.001$ \\
\hline No congestive heart failure & $6668(91)$ & $4978(92)$ & $1690(87)$ & \\
\hline Total & $7362(100)$ & $5417(100)$ & $1945(100)$ & \\
\hline Dementia & $236(3)$ & $154(3)$ & $82(4)$ & .0032 \\
\hline No dementia & $7126(97)$ & $5263(97)$ & $1863(96)$ & \\
\hline Total & $7362(100)$ & $5417(100)$ & $1945(100)$ & \\
\hline Diabetes mellitus & $1223(17)$ & $815(15)$ & $408(21)$ & $<.001$ \\
\hline No diabetes mellitus & $6139(83)$ & $4602(85)$ & $1537(79)$ & \\
\hline Total & $7362(100)$ & $5417(100)$ & $1945(100)$ & \\
\hline Glaucoma & $249(3)$ & $197(4)$ & $52(3)$ & .044 \\
\hline No glaucoma & $7113(97)$ & $5220(96)$ & $1893(97)$ & \\
\hline Total & $7362(100)$ & $5417(100)$ & 1945 (100) & \\
\hline
\end{tabular}


Table 2 Patterns of Care by Sex

\begin{tabular}{|c|c|c|c|c|}
\hline \multirow[t]{2}{*}{ Characteristic } & Overall $(n=7362)$ & Female $(n=5417)$ & Male $(n=1945)$ & $P$ value \\
\hline & \multicolumn{4}{|l|}{ No. (column \%) } \\
\hline \multicolumn{5}{|l|}{ Source of care } \\
\hline Co-managed ${ }^{*}$ & $1828(25)$ & $1366(25)$ & $462(24)$ & \multirow[t]{8}{*}{$<.001$} \\
\hline PCP only ${ }^{\dagger}$ & $1288(17)$ & $1021(19)$ & $267(14)$ & \\
\hline Urologist only ${ }^{\ddagger}$ & $938(13)$ & $374(7)$ & 564 (29) & \\
\hline Gynecologist only & $195(3)$ & $195(4)$ & $0(0)$ & \\
\hline Urogynecologist only ${ }^{\prime}$ & $76(1)$ & $76(1)$ & $0(0)$ & \\
\hline Urologist, gynecologist, and/or urogynecologist only" & $637(9)$ & $633(12)$ & $4(0)$ & \\
\hline Other ${ }^{\#}$ & $2400(33)$ & $1752(32)$ & $648(33)$ & \\
\hline Total & $7362(100)$ & $5417(100)$ & $1945(100)$ & \\
\hline \multicolumn{5}{|l|}{ Initial medication } \\
\hline Darifenacin & $100(1)$ & $75(1)$ & $25(1)$ & \multirow[t]{12}{*}{.006} \\
\hline Fesoterodine & $55(1)$ & $41(1)$ & $14(1)$ & \\
\hline Flavoxate & $9(0)$ & $9(0)$ & $0(0)$ & \\
\hline Hyoscyamine & $83(1)$ & $65(1)$ & $18(1)$ & \\
\hline Imipramine & $133(2)$ & $103(2)$ & $30(2)$ & \\
\hline Mirabegron & $27(0)$ & $20(0)$ & $7(0)$ & \\
\hline Oxybutynin & $1545(21)$ & $1184(22)$ & $361(19)$ & \\
\hline Solifenacin & $428(6)$ & $324(6)$ & $104(5)$ & \\
\hline Tolterodine & $485(7)$ & $359(7)$ & $126(6)$ & \\
\hline Trospium & $91(1)$ & $75(1)$ & $16(1)$ & \\
\hline None & $4406(60)$ & $3162(58)$ & $1244(64)$ & \\
\hline Total & $7362(100)$ & $5417(100)$ & $1945(100)$ & \\
\hline \multicolumn{5}{|l|}{ Treatment } \\
\hline Biofeedback & $10(0)$ & $9(0)$ & $1(0)$ & \multirow[t]{3}{*}{.24} \\
\hline No biofeedback & $7352(100)$ & $5408(100)$ & $1944(100)$ & \\
\hline Total & $7362(100)$ & $5417(100)$ & $1945(100)$ & \\
\hline OnabotulinumtoxinA & $171(2)$ & $131(2)$ & $40(2)$ & \multirow[t]{3}{*}{.36} \\
\hline No onabotulinumtoxinA & $7191(98)$ & $5286(98)$ & $1905(98)$ & \\
\hline Total & $7362(100)$ & $5417(100)$ & $1945(100)$ & \\
\hline Sacral nerve stimulation & $74(1)$ & $56(1)$ & $18(1)$ & \multirow[t]{3}{*}{.68} \\
\hline No sacral nerve stimulation & 7288 (99) & $5361(99)$ & $1927(99)$ & \\
\hline Total & $7362(100)$ & $5417(100)$ & $1945(100)$ & \\
\hline Bladder augmentation & $0(0)$ & $0(0)$ & $0(0)$ & \multirow[t]{3}{*}{ NA } \\
\hline No bladder augmentation & $7362(100)$ & $5417(100)$ & $1945(100)$ & \\
\hline Total & $7362(100)$ & $5417(100)$ & $1945(100)$ & \\
\hline
\end{tabular}

NA, not applicable; PCP, primary care physician.

*Patients with a PCP who also received care from a urologist, gynecologist, and/or urogynecologist

${ }^{\dagger}$ Patients with a PCP who did not receive care from a urologist, gynecologist, or urogynecologist

${ }^{\ddagger}$ Patients with a urologist who did not receive care from a PCP, gynecologist, or urogynecologist

${ }^{5}$ Patients with a gynecologist who did not receive care from a PCP, urologist, or urogynecologist

$\|$ Patients with a urogynecologist who did not receive care from a PCP, gynecologist, or urologist

"Patients with a urologist, gynecologist, and/or urogynecologist (at least two of three) who did not receive care from a PCP

\#Patients who did not receive care from a PCP, urologist, gynecologist, or urogynecologist but received care from other specialists

125 versus $46 ; P<.001)$. An increasing number of $\mathrm{OAB}$ medications were associated with a linear increase in anticholinergic burden: for each $\mathrm{OAB}$ medication prescribed there was an increase in anticholinergic TSDD of 31 (95\% CI, 26-36; $P<.001$ for the increasing trend in anticholinergic burden). 


\section{Discussion}

In this 2-year longitudinal study of patients identified using an EHR phenotype for OAB, only $40 \%$ of patients were prescribed an $\mathrm{OAB}$ medication. Of patients who received an $\mathrm{OAB}$ medication, the mean number of medications prescribed was two and the average duration of prescribing was only 1.5 months. Use of non-medication treatments, like onabotulinumtoxinA, was infrequent, perhaps as it only received US Food and Drug Administration approval for treatment of $\mathrm{OAB}$ in adults not responsive to anticholinergics in 2013.

Compared with our EHR phenotyping approach, studies that identified patients based on medication or diagnosis claims had slightly longer, but still short, treatment durations with high discontinuation rates. Studies using only medication claims - which, by design, could not measure the rate of medication prescribing - generally found longer durations of treatment, generally ranging from 2 to 6 months $[8,16-18]$. One study relying on a single diagnosis code to define OAB patients had medication fill rates over the course of 1 year of 24\% [7]. Another study using diagnosis codes had a same-visit, EHR medication prescribing rate of $17 \%$ [19]. A third study relying on both diagnosis codes and a medication prescription found that $92 \%$ of patients discontinued or switched their first anticholinergic medication over 24 months, with a mean time to discontinuation or switch of 5 months [9]. A systematic review of OAB medication use found that $43-83 \%$ of patients discontinue anticholinergics in the first 30 days; up to half of patients may have experienced "primary nonadherence," in which patients never fill their first prescription [20,21].

Failure to recognize, address, and treat $\mathrm{OAB}$ may leave patients at risk for complications, adverse effects, and with worse quality of life. Guidelines support lifestyle modifications as primary therapy but pharmacologic therapy may be underutilized. Unfortunately, OAB patients with incontinence who initiated treatment have been shown to have poorer outcomes and higher costs than patients without $\mathrm{OAB}$ [22]. $\mathrm{OAB}$ is under-recognized, undertreated, and undermanaged in primary care. Patients do not bring up $\mathrm{OAB}$ with their physicians, primary care clinicians do not screen for $\mathrm{OAB}$, and patients are generally dissatisfied with treatments for $\mathrm{OAB}[2,6,23,24]$. In our cohort, fewer than $20 \%$ of OAB patients were managed in the PCP setting only and fewer than $30 \%$ were co-managed between a PCP and a specialist. Despite the existence of guidance for primary care treatment of patients with $\mathrm{OAB}$ [25], a minority of patients with $\mathrm{OAB}$ seek care, many delay seeking care, few patients are diagnosed, and PCPs may prematurely refer patients for specialty care [24, 26-28]. Guidelines for referral should include failure to respond to pharmacologic therapy, uncertain diagnosis, microscopic or gross hematuria, or suspicion of bladder carcinoma [6].
Despite likely inadequate treatment, an increasing concern about $\mathrm{OAB}$ medications is anticholinergic burden in patients with high cumulative anticholinergic exposure. Studies have found associations between anticholinergic medication and brain atrophy, brain hypometabolism, progression to cognitive impairment, and increased healthcare utilization [29, 30]. Gray and colleagues found that dementia risk increased as the anticholinergic TSDD over 10 years increased when categories of 1-90, 91-365, 366-1095, and over 1095 were used [5]. Bladder antimuscarinics accounted for $10.5 \%$ of TSDD burden. We found a TSDD difference of 79 over 2 years between patients who did and did not receive OAB medications. Clinicians may not be aware of the cognitive risks associated with anticholinergic medications for OAB [31].

Our analysis has limitations that should be considered. First, our novel method of identifying OAB patients remains documentation-dependent. In order to be entered into the cohort, patients had to have at least one coded variable for $\mathrm{OAB}$ and clinicians or coders had to enter additional codes or documentation that indicated symptoms of OAB. Patients with unrecognized symptoms would not have such codes or documentation. Second, our OAB EHR phenotype of course does not have perfect sensitivity or PPV. We would have compared the sensitivity and PPV of our OAB EHR phenotype to other large-scale methods of $\mathrm{OAB}$ identification. However, as of November 2019, a PubMed search revealed no articles that reported the sensitivity or PPV for identifying OAB using claims or electronic health records. A conference presentation found that 25 different OAB-related ICD-9 codes had associations with $\mathrm{OAB}$ medications ranging from 0 to $21 \%$ (mean, $4 \%$ ) [32].

Third, our measures of medication use represent medication prescribing, not fills or actual drug taking. Fourth, our detection period was restricted to 2 years, and may have identified patients with OAB characteristics prior to the identification period or prior receipt of $\mathrm{OAB}$ medications. Fifth, we could not include $\mathrm{OAB}$ health-related quality of life or other patient-reported outcome measures. Sixth, we only had access to documentation within our health system; care provided and documented elsewhere was not included. Seventh, patients were dichotomously defined as either having or not having OAB. We do not have a good method for determining disease duration, severity, or subtype. $O A B$ disease duration and severity could be important in identifying differences between patients cared for by PCPs alone versus patients who saw specialists. OAB severity and subtype (e.g., incontinence-associated) could be associated with different patterns of $\mathrm{OAB}$ medication use. Eighth, we did not collect information about related symptoms, like constipation, which might also be associated with differential $\mathrm{OAB}$ medication use. Finally, as 
our results are based upon our health system, the results presented here may not be generalizable to other systems.

Despite these limitations, strengths of this study include our novel method of identifying an EHR phenotype for $O A B$ and the relatively large sample of $O A B$ patients. EHR phenotypes have the potential to expand understanding about the prevalence and treatment of $\mathrm{OAB}$.

\section{Conclusions}

$\mathrm{OAB}$ is a common, morbid condition that is underrecognized. For patients identified using an OAB EHR phenotype in an integrated healthcare system, physicians prescribed medication to only $40 \%$ of patients over 2 years. Specialists were roughly twice as likely to prescribe medication to patients compared with PCPs. Even for patients who received medication, the average duration of medication use was only 1.5 months. Patients appear to have their symptoms inadequately addressed, as evidenced by the small number of patients who receive active treatment and the very short average duration of treatment. Treated patients who received $O A B$ medications, predominantly antimuscarinics, had an increased anticholinergic burden.

\section{Supplementary information}

Supplementary information accompanies this paper at https://doi.org/10. 1186/s12913-020-05315-1.

Additional file 1: Table S1. 37 OAB Structured Variables. Table S2. Final EHR Phenotype Model Variables and Coefficients. Table S3. Problem List Entries and Diagnosis Codes for Comorbid Conditions.

Table S4. CPT Codes for Procedures. Table S5. Medication Prescribing by Patient Characteristics. Table S6. Cohort Characteristics by Source of Care.

\section{Abbreviations}

BOW: Bag of words; EHR: Electronic health record; ICD-9: International Statistical Classification of Diseases and Related Health Problems; ICS: International Continence Society; LASSO: Least absolute shrinkage and selector operator; OAB: Overactive bladder; PCP: Primary care physician; PPV: Positive predictive value; TSDD: Total standardized daily dose

\section{Acknowledgements}

The authors would like to recognize Sorbarikor Piawah, MD, Peter Olds, MD, and David Rubins, MD for their contributions to chart review.

\section{Authors' contributions}

$J A L$ and HRN were responsible for acquisition of the data. JAL, JSW, HRN, SL, $\mathrm{RSH}, \mathrm{JD}, \mathrm{RMK}$, and KRL made substantial contributions to conception and design; analysis and interpretation of data; drafting and revision of the manuscript for important intellectual content; read and approved the final manuscript; and agree both to be personally accountable for the author's own contributions and to ensure that questions related to the accuracy or integrity of any part of the work, even ones in which the author was not personally involved, are appropriately investigated, resolved, and the resolution documented in the literature.

\section{Funding}

This analysis was supported by a grant from Astellas Pharma, Inc. Two of the co-authors (JD and RMK) are employees of Astellas. Staff from Astellas were involved in the design and conduct of the study; interpretation of the data; preparation, review, and approval of the manuscript; and the decision to submit the manuscript for publication. Astellas was not involved in the collection, management, or analysis of the data.

\section{Availability of data and materials}

The dataset supporting the conclusions of this article is not publically available as the data contain identifiable information from patients who were receiving routine clinical care. An extract may be available from the corresponding author on reasonable request.

\section{Ethics approval and consent to participate}

The Partners HealthCare Human Research Committee approved the protocol (\#2014P000290/BWH). No additional administrative approvals were required. The data were maintained within the Partners HealthCare firewall and were not anonymized. Data are only reported in aggregate in this manuscript.

\section{Consent for publication}

Not applicable.

\section{Competing interests}

The authors declare that they have no competing interests.

\section{Author details}

${ }^{1}$ Division of General Internal Medicine and Geriatrics, Northwestern University Feinberg School of Medicine, 750 N. Lake Shore Drive, 10th Floor, Chicago, IL 60611, USA. ${ }^{2}$ Center for Surgery and Public Health, Brigham and Women's Hospital, Harvard Medical School, Boston, MA, USA. ${ }^{3}$ Division of General Internal Medicine and Primary Care, Brigham and Women's Hospital, Harvard Medical School, Boston, MA, USA. ${ }^{4}$ Department of Physical Medicine and Rehabilitation, Vanderbilt University Medical Center, Nashville, TN, USA. ${ }^{5}$ Astellas Pharma Global Development, Northbrook, IL, USA. ${ }^{6}$ Division of Urology, Brigham and Women's Hospital, Harvard Medical School, Boston, MA, USA.

Received: 14 August 2018 Accepted: 10 May 2020

Published online: 20 May 2020

\section{References}

1. Stewart WF, Van Rooyen JB, Cundiff GW, et al. Prevalence and burden of overactive bladder in the United States. World J Urol. 2003;20(6):327-36.

2. Milsom I, Abrams P, Cardozo L, Roberts RG, Thuroff J, Wein AJ. How widespread are the symptoms of an overactive bladder and how are they managed? A population-based prevalence study. BJU Int. 2001;87(9):760-6.

3. Gormley EA, Lightner DJ, Burgio KL, et al. Diagnosis and treatment of overactive bladder (non-neurogenic) in adults: AUA/SUFU guideline. J Urol. 2012;188(6 Suppl):2455-63.

4. Campbell NL, Boustani MA, Lane KA, et al. Use of anticholinergics and the risk of cognitive impairment in an African American population. Neurology. 2010;75(2):152-9.

5. Gray SL, Anderson ML, Dublin S, et al. Cumulative use of strong anticholinergics and incident dementia: a prospective cohort study. JAMA Intern Med. 2015;175(3):401-7.

6. Macdiarmid SA. Maximizing the treatment of overactive bladder in the elderly. Rev Urol. 2008;10(1):6-13.

7. Helfand BT, Evans RM, McVary KT. A comparison of the frequencies of medical therapies for overactive bladder in men and women: analysis of more than 7.2 million aging patients. Eur Urol. 2010;57(4):586-91.

8. Wagg A, Compion G, Fahey A, Siddiqui E. Persistence with prescribed antimuscarinic therapy for overactive bladder: a UK experience. BJU Int. 2012;110(11):1767-74.

9. Chancellor MB, Migliaccio-Walle K, Bramley TJ, Chaudhari SL, Corbell C, Globe D. Long-term patterns of use and treatment failure with anticholinergic agents for overactive bladder. Clin Ther. 2013;35(11):1744-51.

10. Pathak J, Kho AN, Denny JC. Electronic health records-driven phenotyping: challenges, recent advances, and perspectives. J Am Med Inform Assoc. 2013;20(e2):e206-11.

11. Liao KP, Cai T, Savova GK, et al. Development of phenotype algorithms using electronic medical records and incorporating natural language processing. BMJ. 2015;350:h1885.

12. Abrams P, Cardozo L, Wagg A, Wein A, editors. Incontinence, 6th ed. Bristol, UK: ICI-ICS. International Continence Society; 2017. 
13. Tibshirani R. The lasso method for variable selection in the cox model. Stat Med. 1997;16(4):385-95.

14. Tibshirani R. Regression shrinkage and selection via the lasso. J R Statist Soc B. 1996:58(1):267-88.

15. Hanlon JT, Boudreau RM, Roumani YF, et al. Number and dosage of central nervous system medications on recurrent falls in community elders: the health, aging and body composition study. J Gerontol A Biol Sci Med Sci. 2009:64A(4):492-8.

16. Nitti WW, Rovner ES, Franks B, et al. Persistence with mirabegron versus tolterodine in patients with overactive bladder. Am J Pharm Benefits. 2016; 8(2):e25-33.

17. Brostrøm S, Hallas J. Persistence of antimuscarinic drug use. Eur I Clin Pharmacol. 2009;65(3):309-14.

18. Linner L, Schioler H, Samuelsson E, Milsom I, Nilsson F. Low persistence of anticholinergic drug use in Sweden. Eur J Clin Pharmacol. 2011;67(5):535-6.

19. Moskowitz D, Adelstein SA, Lucioni A, Lee UJ, Kobashi KC. Use of third line therapy for overactive bladder in a practice with multiple subspecialty providers-are we doing enough? J Urol. 2018;199(3):779-84.

20. Sexton CC, Notte SM, Maroulis C, et al. Persistence and adherence in the treatment of overactive bladder syndrome with anticholinergic therapy: a systematic review of the literature. Int J Clin Pract. 2011;65(5):567-85.

21. Fischer MA, Stedman MR, Lii J, et al. Primary medication non-adherence: analysis of 195,930 electronic prescriptions. J Gen Intern Med. 2010;25(4): 284-90.

22. Yehoshua A, Chancellor M, Vasavada S, et al. Health resource utilization and cost for patients with incontinent overactive bladder treated with anticholinergics. J Manag Care Spec Pharm. 2016;22(4):406-13.

23. Shaw C, Tansey R, Jackson C, Hyde C, Allan R. Barriers to help seeking in people with urinary symptoms. Fam Pract. 2001;18(1):48-52.

24. Dmochowski RR, Newman DK. Impact of overactive bladder on women in the United States: results of a national survey. Curr Med Res Opin. 2007; 23(1):65-76.

25. Rosenberg MT, Witt ES, Barkin J, Miner M. A practical primary care approach to overactive bladder. Can J Urol. 2014;21(Suppl 2):2-11.

26. Coyne KS, Sexton CC, Kopp ZS, Ebel-Bitoun C, Milsom I, Chapple C. The impact of overactive bladder on mental health, work productivity and health-related quality of life in the UK and Sweden: results from EpiLUTS. BJU Int. 2011;108(9):1459-71.

27. Cheung WW, Blank W, Borawski D, Tran W, Bluth MH. Prevalence of overactive bladder, its under-diagnosis, and risk factors in a male urologic veterans population. Int J Med Sci. 2010;7(6):391-4.

28. Smith AL, Nissim HA, Le TX, et al. Misconceptions and miscommunication among aging women with overactive bladder symptoms. Urology. 2011; 77(1):55-9.

29. Campbell NL, Perkins AJ, Bradt P, et al. Association of anticholinergic burden with cognitive impairment and health care utilization among a diverse ambulatory older adult population. Pharmacotherapy. 2016;36(11):1123-31.

30. Risacher SL, McDonald BC, Tallman EF, et al. Association between anticholinergic medication use and cognition, brain metabolism, and brain atrophy in cognitively normal older adults. JAMA Neurol. 2016;73(6):721-32.

31. Araklitis G, Thiagamoorthy G, Hunter J, Rantell A, Robinson D, Cardozo L. Anticholinergic prescription: are healthcare professionals the real burden? Int Urogynecol J. 2017;28(8):1249-56.

32. Espinosa R, Davis M, Johnson SJ, Walker D, Ng DB, Gooch K. Impact of individual diangosis codes on database estimates of overactive bladder. ISPOR 2017; May 20-24, 2017; Boston, MA USA.

\section{Publisher's Note}

Springer Nature remains neutral with regard to jurisdictional claims in published maps and institutional affiliations.

Ready to submit your research? Choose BMC and benefit from:

- fast, convenient online submission

- thorough peer review by experienced researchers in your field

- rapid publication on acceptance

- support for research data, including large and complex data types

- gold Open Access which fosters wider collaboration and increased citations

- maximum visibility for your research: over $100 \mathrm{M}$ website views per year

At BMC, research is always in progress.

Learn more biomedcentral.com/submissions 